This is an electronic reprint of the original article. This reprint may differ from the original in pagination and typographic detail.

Author(s): Hurmalainen, Juha; Land, Michael A.; Robertson, Katherine N.; Roberts, Christopher; Morgan, Ian; Tuononen, Heikki; Clyburne, Jason A. C.

Title: $\quad$ Comment on "Crystallographic Snapshot of an Arrested Intermediate in the Biomimetic Activation of CO2"

Year: $\quad 2015$

Version:

Please cite the original version:

Hurmalainen, J., Land, M. A., Robertson, K. N., Roberts, C., Morgan, I., Tuononen, H., \& Clyburne, J. A. C. (2015). Comment on "Crystallographic Snapshot of an Arrested Intermediate in the Biomimetic Activation of CO2". Angewandte Chemie International Edition, 54(26), 7484-7487. https://doi.org/10.1002/anie.201411654

All material supplied via JYX is protected by copyright and other intellectual property rights, and duplication or sale of all or part of any of the repository collections is not permitted, except that material may be duplicated by you for your research use or educational purposes in electronic or print form. You must obtain permission for any other use. Electronic or print copies may not be offered, whether for sale or otherwise to anyone who is not an authorised user. 


\section{Comment on "Crystallographic Snapshot of an Arrested Intermediate in the Biomimetic Activation of $\mathrm{CO}_{2}{ }^{3 * * *}$}

Juha Hurmalainen, ${ }^{1,2}$ Michael A. Land, ${ }^{1}$ Katherine N. Robertson, ${ }^{1}$ Christopher J. Roberts, ${ }^{2}$ lan S. Morgan, ${ }^{2}$ Heikki M. Tuononen, ${ }^{2 *}$ and Jason A.C. Clyburne ${ }^{1^{*}}$

1 The Atlantic Centre for Green Chemistry, Department of Chemistry, Saint Mary's University, Halifax, Nova Scotia, B3H 3C3, Canada. Tel: 019024205827.

2 University of Jyväskylä, Department of Chemistry, Nanoscience Center, P.O. Box 35, FI-40014, University of Jyväskylä, Finland. Tel: 358452358588.

*Correspondence to: jason.clyburne@smu.ca; heikki.m.tuononen@jyu.fi

** We thank the Natural Sciences and Engineering Research Council of Canada (through the Discovery Grants Program to JACC) and the Academy of Finland (through its Research Fellowship to HMT). JACC acknowledges support from the Canada Research Chairs Program, the Canadian Foundation for Innovation and the Nova Scotia Research and Innovation Trust Fund. HMT acknowledges support from the Academy of Finland, the Foundation for Research of Natural Resources in Finland and the University of Jyväskylä. This work was also supported in part by Encana Corporation (Deep Panuke Education \& Training and Research \& Development Fund), Springboard and the NSF Graduate Research Opportunities Worldwide Program (CJR). We are grateful to NMR-3 (Dalhousie University) for NMR data acquisition, Dr. Mark Obrovac (Dalhousie University) for X-ray powder data acquisition and Dr. Christa Brosseau (Saint Mary's University) for Raman data acquisition. We also thank Dr. Phillip Jessop for his helpful insights. Metrical parameters for tetra- $n$-butylammonium acetate are available free of charge from the Cambridge Crystallographic Data Centre, under reference number CCDC 1036823. 
Out of focus: A recent paper, titled a "Crystallographic snapshot of an arrested intermediate in the biomimetic activation of $\mathrm{CO}_{2}$ ", published in this journal describes the synthesis of tetra- $n$-butylammonium bicarbonate. The authors performed a single crystal X-ray study which revealed a putative species described as an incipient hydroxide ion engaging in a long, and presumably weak, interaction with $\mathrm{CO}_{2}$. Our recent exploration of the coordination chemistry of $\mathrm{CO}_{2}$ with small ions leads us to believe that such an exceptional bonding situation is unlikely. Instead, we argue that the crystal structure is that of tetra- $n$-butylammonium acetate and therefore not representative of the bulk powder from the synthesis.

Keywords: X-ray crystallography, structure elucidation, computational chemistry, carbon dioxide

In a recent article, "Crystallographic snapshot of an arrested intermediate in the biomimetic activation of $\mathrm{CO}_{2}$ ", Ackermann et al. report the crystallographic characterization of an intermediate in the formation of tetra- $n$-butylammonium bicarbonate, $\left[\left(n-\mathrm{C}_{4} \mathrm{H}_{9}\right)_{4} \mathrm{~N}\right]\left[\mathrm{HCO}_{3}\right]$, which displays a remarkably long $\mathrm{C}-\mathrm{OH}$ bond of 1.563(6) A..$^{[1]}$ The paper immediately caught our attention as we are also interested in the chemical capture and conversion of $\mathrm{CO}_{2 .}{ }^{[2]}$ Recently we reported the complete characterization of a salt containing the cyanoformate anion (1), $\left[\mathrm{NCCO}_{2}\right]^{-}$, a simple adduct of cyanide and $\mathrm{CO}_{2}$ which had long eluded characterization. ${ }^{[3]}$ Interestingly, some of the rarest adducts of $\mathrm{CO}_{2}$ are, in fact, the simplest. For instance, stable solid derivatives of simple coordination complexes of halides or pseudo-halides with $\mathrm{CO}_{2}$ are virtually unknown. Other than cyanoformate and bicarbonate, only the fluorocarbonate anion, $\left[\mathrm{FCO}_{2}\right]^{-}$, has been prepared. ${ }^{[4]}$ Naturally, a paper describing a very atypical geometry for the bicarbonate anion was of great interest to us. 

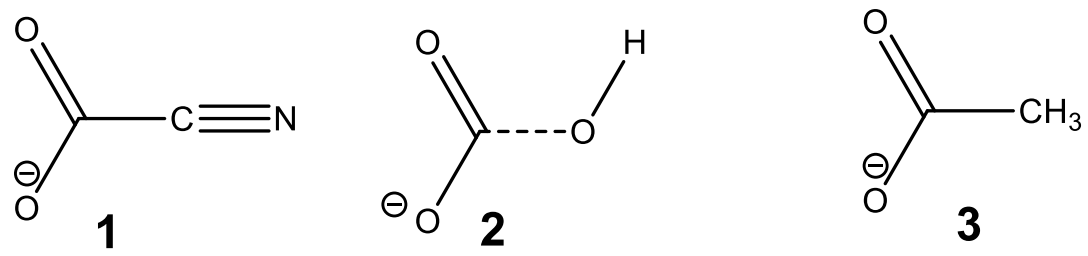

The experimental work of Ackermannet al. can be summarized as follows. Gaseous $\mathrm{CO}_{2}$ was bubbled through an aqueous solution of tetra- $n$-butylammonium hydroxide, $\left[n \mathrm{Bu}{ }_{4} \mathrm{~N}\right] \mathrm{OH}$, until a neutral $\mathrm{pH}$ was reached. An anhydrous salt was then obtained by azeotropically dehydrating the reaction mixture using successive portions of diethyl ether. This yielded a colourless powder which was spectroscopically (IR, Raman, and ${ }^{1} \mathrm{H}$ and ${ }^{13} \mathrm{C} \mathrm{NMR}$ ) identified as tetra- $n$-butylammonium bicarbonate, $\left[n \mathrm{Bu}_{4} \mathrm{~N}\right] \mathrm{HCO}_{3}$. Slow evaporation of a saturated diethyl ether solution of the powder gave colourless crystals in an unreported yield. The data from a subsequent X-ray structural study was interpreted in terms of an unprecedented arrested anionic intermediate, $\left[\mathrm{O}_{2} \mathrm{C} \cdots \mathrm{OH}\right]^{-}(2)$, which is encapsulated within a hydrophobic host scaffold generated by the tetra- $n$ butylammonium, $n \mathrm{Bu}{ }_{4} \mathrm{~N}$, cations. The scaffold holds two symmetry-related anions in a head-to-tail orientation with the two hydroxyl groups separated by a long $\mathrm{O}$... $\mathrm{O}$ distance of $4.71 \AA$. Due to this structural arrangement and the lack of hydrogen bond acceptors in the cation, the hydroxyl groups are not involved in any secondary bonding interactions, which is rather surprising. However, the crystal structure shows several $\mathrm{C}-\mathrm{H}$ moieties on the cation in close enough proximity to form weak $\mathrm{C}-\mathrm{H}$... $\mathrm{O}$ interactions with the anion. These interactions are postulated to help to stabilize the structure of the arrested intermediate though no justification (other than structural data) is given.

The results reported by Ackermann et al. for $\left[n \mathrm{Bu}_{4} \mathrm{~N}\right]\left[\mathrm{O}_{2} \mathrm{C} \cdots \mathrm{OH}\right]$ contrast with our experiences with cyanoformate. ${ }^{[3]}$ In our structure, the anion (1) featured an $s p-s p^{2}$ carbon-carbon bond of normal length,1.480(9) $\AA$, even though it was readily cleaved in solvents of higher polarity, forming $\mathrm{CO}_{2}$ and $\mathrm{CN}^{-}$. In a similar fashion, when trapped inside a hydrophobic pocket, bicarbonate would be expected to contain a regular $\mathrm{C}-\mathrm{OH}$ bond unless distorted by strong inter-ionic interactions. The hydrophobic pocket discussed by Ackermann et al. is indeed structurally interesting but it offers no apparent explanation for the stabilization of the putative long $\mathrm{C} \ldots \mathrm{O}$ bond as only weak $\mathrm{C}-\mathrm{H} \ldots \mathrm{O}$ 
contacts with the $\mathrm{CO}_{2}$ end of the anion are present. In fact, the $\mathrm{C} \cdots \mathrm{O}$ bond length in $\left[n \mathrm{Bu}_{4} \mathrm{~N}\right]\left[\mathrm{O}_{2} \mathrm{C} \cdots \mathrm{OH}\right]$ is reminiscent of the $\mathrm{C}-\mathrm{C}$ bond distance calculated by us for an isolated cyanoformate anion in vacuum, $1.544 \AA$ (CCSD(T)/aug-cc-pVTZ). We therefore considered the possibility that the salt reported by Ackermann et al. could contain the common acetate anion, $\left[\mathrm{O}_{2} \mathrm{CCH}_{3}\right]^{-}(3)$, with a $\mathrm{C}-\mathrm{C}$ bond of normal length. We contacted the corresponding authors of the original work and informed them about our concerns, but they felt it "unnecessary to revisit the chemistry at this time". Since we could only access the cif file for $\left[n \mathrm{Bu}_{4} \mathrm{~N}\right]\left[\mathrm{O}_{2} \mathrm{C} \cdots \mathrm{OH}\right]$ from the CCDC repository, ${ }^{[5]}$ a straightforward reinterpretation of the original crystallographic data was impossible. For this reason, we chose to crystallize tetra- $n$-butylammonium acetate, $\left[n \mathrm{Bu}_{4} \mathrm{~N}\right]\left[\mathrm{O}_{2} \mathrm{CCH}_{3}\right]$, and determine its structure using single crystal $\mathrm{X}$-ray diffraction. The results, supported by additional computational work, show that a more plausible explanation for the exceptional arrested intermediate reported by Ackermann et al. is the common acetate anion with a typical C-C bond length of 1.537(3) $\AA$.

\section{X-ray Crystallography}

A fresh sample of $[n \mathrm{Bu} 4 \mathrm{~N}]\left[\mathrm{O}_{2} \mathrm{CCH}_{3}\right]$ was purchased from Sigma-Aldrich and opened in an inert atmosphere. A single crystal was removed directly from the bottle and a complete X-ray crystallographic study $(125 \mathrm{~K})$ was performed on it as described in the Supporting Information. Once the low temperature data collection was finished, a set of room temperature data was also collected for the same crystal. In addition, a solution of $\left[n \mathrm{Bu}_{4} \mathrm{~N}\right]\left[\mathrm{O}_{2} \mathrm{CCH}_{3}\right]$ in dry acetonitrile was stirred for 24 hours under argon in the presence of $3 \AA$ molecular sieves. The solvent was then pumped off and the colourless precipitate was brought into an inert atmosphere. A saturated diethyl ether solution of the powder was allowed to evaporate for 3 days to produce colourless platelike crystals. The structure of one of these crystals $(123 \mathrm{~K})$ was found to be identical to that determined from the crystal of the fresh sample and is not discussed further.

Table 1 shows a comparison of unit cell parameters for the structure described by Ackermann et al. to those obtained in this work for $\left[n B \mathrm{nu}_{4} \mathrm{~N}\right]\left[\mathrm{O}_{2} \mathrm{CCH}_{3}\right]$. We are unsure of the actual data collection temperature for $\left[n \mathrm{Bu}_{4} \mathrm{~N}\right]\left[\mathrm{O}_{2} \mathrm{C} \cdots \mathrm{OH}\right]$ as conflicting information 
was found in the Supporting Information for the original paper and in the cif file obtained from the CCDC. ${ }^{[5]}$ The systematic absences for all the data sets indicate that the space group for $\left[n \mathrm{Bu}_{4} \mathrm{~N}\right]\left[\mathrm{O}_{2} \mathrm{CCH}_{3}\right]$ is $P 21 / n$ (\#14) which is also the space group reported for $\left[n \mathrm{Bu}_{4} \mathrm{~N}\right]\left[\mathrm{O}_{2} \mathrm{C} \cdots \mathrm{OH}\right]$ by Ackermann et al. A comparison of the unit cell parameters (Table 1) shows that the data are for closely related substances if not for the identical material.

Table 1: Unit cell parameters for the structure described by Ackermann et al. compared to those obtained in this work for $\left[n B u_{4} N\right]\left[\mathrm{O}_{2} \mathrm{CCH}_{3}\right]$.

\begin{tabular}{ccccccc}
\hline & $\begin{array}{c}\text { Temperature } \\
{[\mathrm{K}]}\end{array}$ & $\boldsymbol{a}$ & $\boldsymbol{b}$ & $\boldsymbol{c}$ & $\boldsymbol{\beta}$ & $\begin{array}{c}\text { Volume } \\
{\left[\AA^{3}\right]}\end{array}$ \\
\hline original work & unknown & $10.755(2)$ & $13.497(2)$ & $13.948(2)$ & $101.876(2)$ & $1981.4(5)$ \\
this work & 125 & $10.7273(12)$ & $13.3080(15)$ & $13.9495(15)$ & $101.9615(13)$ & $1948.2(6)$ \\
this work & 297 & $10.8277(16)$ & $13.799(2)$ & $13.968(2)$ & $101.1851(19)$ & $2047.3(9)$ \\
\hline
\end{tabular}

During the refinement of the $125 \mathrm{~K}$ structure of $[n \mathrm{Bu} 4 \mathrm{~N}]\left[\mathrm{O}_{2} \mathrm{CCH}_{3}\right]$, care was taken to make sure that all the heavy atoms of the anion had been correctly assigned. To do this, in the anisotropic refinement, once all the atoms of the cation (including hydrogens) had been modelled, each atom of the anion was studied individually in turn. For every atom, a cycle of refinement was carried out with that atom assigned sequentially as $B$, $\mathrm{C}, \mathrm{N}, \mathrm{O}$ or $\mathrm{F}$. The refinement statistics (R1, wR2 and GoF) were observed and the atom type giving the minimal values chosen as the correct fit for that position. Although this procedure is tedious and a technical overkill for what is an essentially a pure crystalline salt, the results will be of interest when comparing our structural data with that reported by Ackermann et al. for $\left[n \mathrm{Bu}_{4} \mathrm{~N}\right]\left[\mathrm{O}_{2} \mathrm{C} \cdots \mathrm{OH}\right]$. A summary of the most important results, for the C18 carbon of the terminal methyl group of the acetate anion, are summarized in Table 2. For our data, there is complete agreement with the anion being an acetate ion, as expected. 
Table 2: Statistical and other parameters for the anisotropic refinement of $\left[n \mathrm{Bu}_{4} \mathrm{~N}\right]\left[\mathrm{O}_{2} \mathrm{CCH}_{3}\right]$ at $125 \mathrm{~K}$ where the terminal $\mathrm{C} 18$ atom of the anion has been sequentially replaced by other second row elements to judge the quality of the model.[a]

\begin{tabular}{ccccc}
\hline X & B & C18 & N & 03 \\
\hline R1 & 0.0646 & 0.0555 & 0.0571 & 0.0678 \\
wR2 & 0.2290 & 0.1932 & 0.1955 & 0.2268 \\
GoF & 1.419 & 1.188 & 1.202 & 1.401 \\
positive Q [e $\left.\AA^{-3}\right]$ & 0.81 & 0.47 & 0.41 & 0.66 \\
negative Q [e $\left.\AA^{-3}\right]$ & -0.20 & -0.18 & -0.32 & -0.65 \\
Ueq & 0.03658 & 0.04773 & 0.06746 & 0.09659 \\
C17-X distance [̊̊] & $1.5364(34)$ & $1.5374(28)$ & $1.5416(28)$ & $1.5421(33)$ \\
[a] The atom C18 corresponds to our refinement (complete except for the methyl \\
hydrogens on the anion), whereas O3 corresponds to a model, using our data, of the \\
structure reported by Ackermann et al. (complete except for the proton on O3).
\end{tabular}

Next, the geometrical data for our O3 refinement (Table 2) was compared to the structural parameters reported by Ackermann et al. Geometrical parameters were determined to be significantly different if the difference $(\Delta)$ between the two was larger than three times the standard uncertainty $(\sigma)$, i.e. $99.7 \%$ confidence interval. The bond lengths and angles reported for $\left[n \mathrm{Bu}_{4} \mathrm{~N}\right]\left[\mathrm{O}_{2} \mathrm{C} \cdots \mathrm{OH}\right]$ were taken from the Supporting Information of the original publication. We note, however, that the values reported in the cif file obtained from the $\mathrm{CCDC}^{[5]}$ are, again, slightly different from that reported in the article.

Full data from the structural comparison is given in the Supporting Information. From the analysis, it is immediately evident that the two models are equivalent and represent the same structure. Only one bond in the entire model (the anion $\mathrm{C}(17)-\mathrm{O}(2)$ bond) is significantly different, for a reason not readily apparent to us. The crucial comparison between the $\mathrm{C}(17) \cdots \mathrm{O}(3)$ bond in the two structures shows that there is no significant difference in the bond length and our model accurately replicates the large 
thermal motion of the $\mathrm{O}(3)$ atom reported by Ackermann et al. We also note that all of the bond angles in the two models, including both the anion and the cation, are not significantly different. A similar comparison between our $\mathrm{O} 3$ model and the actual C18 refinement shows that the structural parameters are not considerably affected even in this case. This is clearly seen in Figure 1 which features an overlay of the thermal ellipsoid plots for $\left[n \mathrm{Bu}_{4} \mathrm{~N}\right]\left[\mathrm{O}_{2} \mathrm{CCH}_{3}\right]$ (our refinement) and $\left[n \mathrm{Bu}_{4} \mathrm{~N}\right]\left[\mathrm{O}_{2} \mathrm{C} \cdots \mathrm{OH}\right]$ (data reported by Ackermann et al.). It is evident that the two structures are completely superimposable on one another, indicative of a common origin.

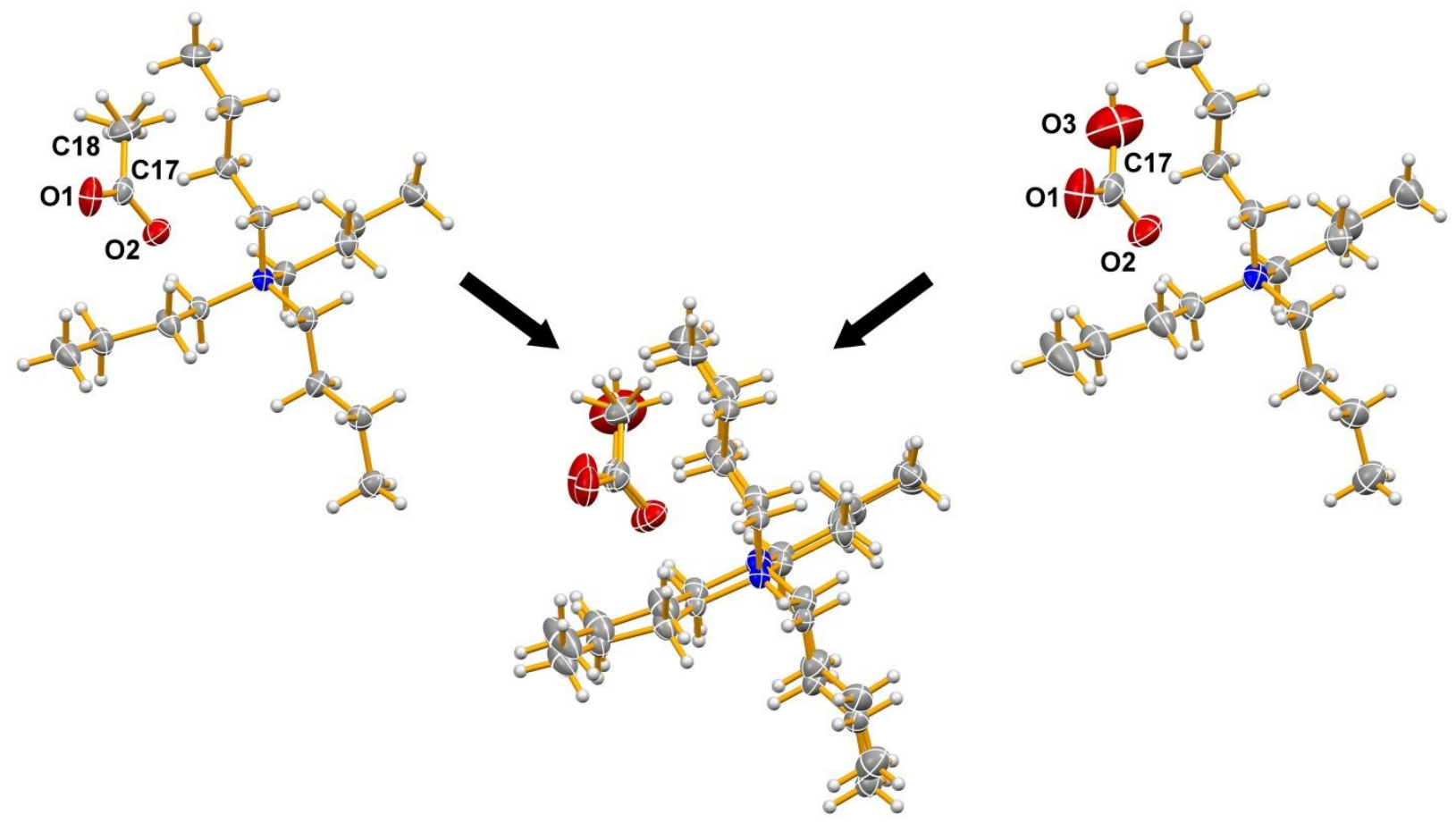

Figure 1: Thermal ellipsoid plots (50\% probability) for $\left[n \mathrm{Bu}_{4} \mathrm{~N}\right]\left[\mathrm{O}_{2} \mathrm{CCH}_{3}\right]$ at $125 \mathrm{~K}$ (left, this work) and for the proposed $\left[n \mathrm{Bu}_{4} \mathrm{~N}\right]\left[\mathrm{O}_{2} \mathrm{C} \cdots \mathrm{OH}\right]$ salt (right, data from Ackermann et al.), along with an overlay of the two structures (middle). The overlay has been left slightly offset to better highlight the structural similarities. All diagrams were prepared using the program Mercury CSD 3.3.1.[6]

We conclude the structural comparison by considering the inter-ionic interactions in $\left[n \mathrm{Bu}_{4} \mathrm{~N}\right]\left[\mathrm{O}_{2} \mathrm{CCH}_{3}\right]$ and $[n \mathrm{Bu} 4 \mathrm{~N}]\left[\mathrm{O}_{2} \mathrm{C} \cdots \mathrm{OH}\right]$ (full analysis is given in the Supporting 
Information). Overall, a remarkably similar arrangement of anions in the pocket formed by the cations is observed in both structures. We also note that there is one $\mathrm{C}-\mathrm{H} \cdots \mathrm{O}$ interaction of reasonable length $(\mathrm{C}(1)-\mathrm{H}(1 \mathrm{~A}) \cdots \mathrm{O}(1))$ present in both structures that was not identified by Ackermann et al. The average difference in the $d(\mathrm{H} \cdots \mathrm{A})$ distances is only $0.06 \AA$ and that of the $\angle(\mathrm{DHA})$ angles is $4^{\circ}$. The head-to-tail orientation of the $\left[\mathrm{O}_{2} \mathrm{C} \cdots \mathrm{OH}\right]^{-}$anions in the structural analysis of Ackermann et al. lead to an $\mathrm{O} \cdots \mathrm{O}$ distance of $4.71 \AA$ between the two hydroxyl groups. In our refinement of $[n \mathrm{Bu} 4 \mathrm{~N}]\left[\mathrm{O}_{2} \mathrm{CCH}_{3}\right]$, the shortest $\mathrm{C}(18) \cdots \mathrm{C}(18) \# 3$ contact was found to be $4.665(4) \AA$, symmetry \#3 being $-x+2,-y,-z+1$ (see Figure 2). The two values are nearly equal, differing by only $0.04 \AA$ over the rather large distance.

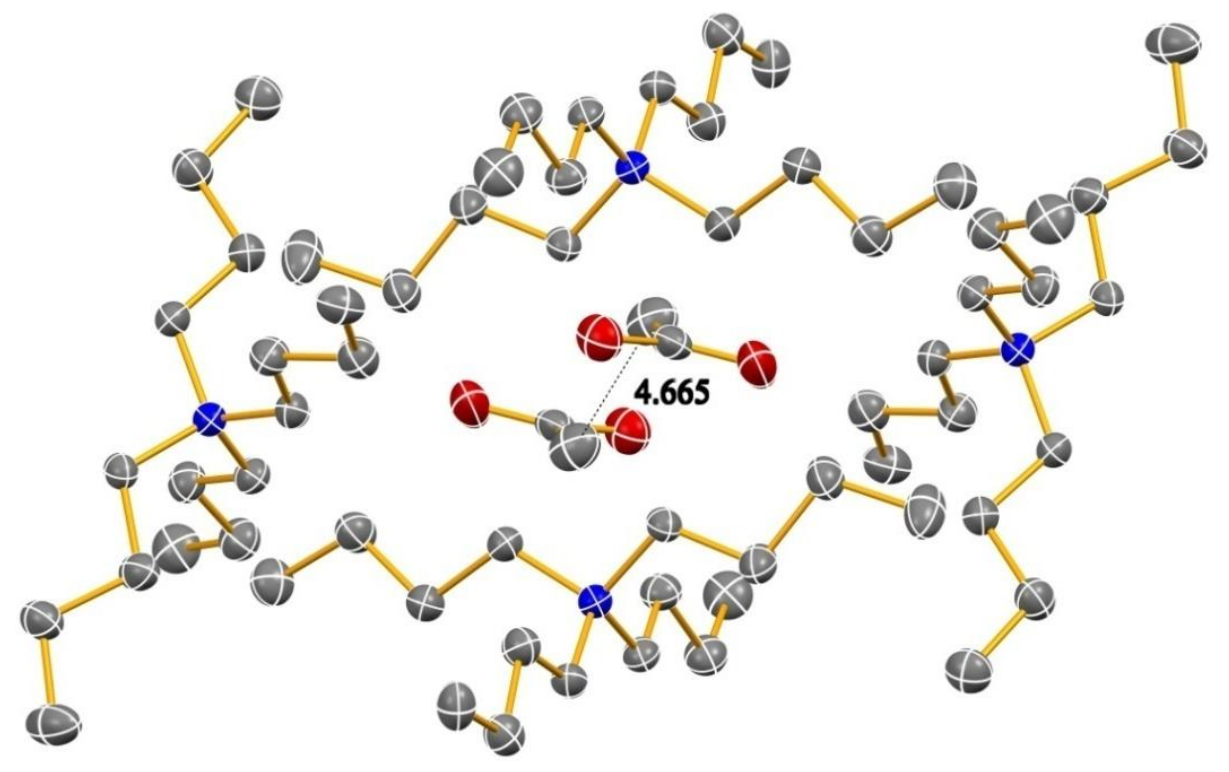

Figure 2: The pocket formed by $n \mathrm{Bu}_{4} \mathrm{~N}$ cations, enclosing a pair of acetate anions, from the final structure of $\left[n \mathrm{Bu}_{4} \mathrm{~N}\right]\left[\mathrm{O}_{2} \mathrm{CCH}_{3}\right]$ at $125 \mathrm{~K}$. Hydrogen atoms have been removed for clarity. The shortest $C(18) \cdots C(18)$ contact in the structure, 4.665(4) $\AA$, is shown.

\section{Computational Studies}

The detailed crystallographic analysis of $\left[n \mathrm{Bu}_{4} \mathrm{~N}\right]\left[\mathrm{O}_{2} \mathrm{CCH}_{3}\right]$ lends very strong support to our proposal that the structure of $\left[n B u_{4} N\right]\left[\mathrm{O}_{2} \mathrm{C} \cdots \mathrm{OH}\right]$ reported by Ackermann et al. is, in fact, that of $\left[n \mathrm{Bu}_{4} \mathrm{~N}\right]\left[\mathrm{O}_{2} \mathrm{CCH}_{3}\right]$. However, since we have no access to the 
original crystallographic data, there remains a possibility, that the two compounds are in fact different and simply isostructural. For this reason, we performed geometry optimizations for bicarbonate and acetate anions in the gas phase as well as within the hydrophobic pocket formed by six $n \mathrm{~B} \mathrm{u}_{4} \mathrm{~N}$ cations.

First, the geometry of a free bicarbonate anion was optimized in the gas phase at the $\operatorname{CCSD}(\mathrm{T})-\mathrm{F} 12 \mathrm{~b} / \mathrm{VTZ}-\mathrm{F} 12$ level of theory. Our results parallel those of Ackermann et al. and show that the optimized $\mathrm{C}-\mathrm{OH}$ bond length is $1.433 \AA$ while the OCO bond angle is $132.3^{\circ}$. Nearly the same set of values is obtained using dispersion corrected density functional theory (PBE1PBE-D3BJ/def-TZVP): $d(\mathrm{C}-\mathrm{OH})=1.437 \AA$ and $\angle(\mathrm{OCO})$ $=132.4^{\circ}$. In a similar fashion, the $\operatorname{CCSD}(\mathrm{T})-\mathrm{F} 12 \mathrm{~b} / \mathrm{VTZ}-\mathrm{F} 12$ optimized geometry of an acetate anion $\left(\left(d(\mathrm{C}-\mathrm{C})=1.552 \AA\right.\right.$ and $\left.\angle(\mathrm{OCO})=128.8^{\circ}\right)$ is reproduced well at the computationally much less expensive PBE1PBE-D3BJ/def-TZVP level $((d(C-C)=1.557$ $\AA$ and $\left.\angle(O C O)=129.1^{\circ}\right)$. We therefore feel confident that the PBE1PBE-D3BJ/defTZVP method can be safely used to optimize the structures of the anions in an environment mimicking the crystal structure as closely as possible.

The structure of the hydrophobic pocket, consisting of $6 n \mathrm{Bu}_{4} \mathrm{~N}$ cations and 2 anions, was extracted from the X-ray data. Full structural optimization of the anions, started from their crystallographic geometries, was then carried out within the environment provided by the $n \mathrm{Bu}_{4} \mathrm{~N}$ cations, which were completely frozen to the places they adopt in the crystal structure. We note that no restraints to the location of the anions in the structures were enforced other than the overall $C_{\mathrm{i}}$ symmetry.

The optimization conducted for acetate inside the hydrophobic pocket shows that the metrical parameters of the anion are in good agreement with its gas phase geometry: $d(\mathrm{C}-\mathrm{C})=1.531 \AA$ and $\angle(\mathrm{OCO})=126.2^{\circ}$. The result for the optimized bicarbonate anion is similar, $d(\mathrm{C}-\mathrm{OH})=1.393 \AA$ and $\angle(\mathrm{OCO})=129.7^{\circ}$. This indicates that the weak $\mathrm{C}-\mathrm{H} \cdots \mathrm{O}$ interactions are not able to support the long $\mathrm{C} \cdots \mathrm{O}$ bond in $[n \mathrm{Bu} 4 \mathrm{~N}]\left[\mathrm{O}_{2} \mathrm{C} \cdots \mathrm{OH}\right]$. Consequently, even if $\left[n \mathrm{Bu}_{4} \mathrm{~N}\right]\left[\mathrm{O}_{2} \mathrm{C} \cdots \mathrm{OH}\right]$ were isostructural with $[n \mathrm{Bu} 4 \mathrm{~N}]\left[\mathrm{O}_{2} \mathrm{CCH}_{3}\right]$, the bicarbonate anion would be expected to have a conventional C-O bond. 


\section{Discussion}

In light of the crystallographic and computational data reported herein, we believe that the crystal structure of $\left[n \mathrm{Bu}_{4} \mathrm{~N}\right]\left[\mathrm{O}_{2} \mathrm{C} \cdots \mathrm{OH}\right]$ reported by Ackermann et al. is in fact that of $\left[n \mathrm{Bu}_{4} \mathrm{~N}\right]\left[\mathrm{O}_{2} \mathrm{CCH}_{3}\right]$. There are also a number of other factors in the original publication that support the plausibility of our interpretation. First, even though a new structure was reported, no elemental analysis of the bulk powder (or the crystalline product) was provided. It is therefore impossible to judge the purity of the material although the reported spectroscopic data appears clean. Second, the paper by Ackermann et al. gives no experimental data that actually ties the reported crystal structure to the bulk powder. There is simply no way to know whether the chosen crystal is representative of the bulk sample. Third, the authors provide the following synthetic information: "The benchmark hydrogen carbonate salt $\mathbf{2}$ was prepared through a modified literature procedure, in which $\mathrm{CO}_{2}$ was bubbled slowly through an aqueous solution of 1 (1.5 M [nBu4N]OH) until a neutral $\mathrm{pH}$ value was attained." We note that the synthetic reference provided by Ackermann et al. does not describe the preparation of $\left[n \mathrm{Bu}_{4} \mathrm{~N}\right] \mathrm{HCO}_{3}$ but rather that of three $\left[n \mathrm{Bu}_{4} \mathrm{~N}\right] \cdot \mathrm{ASM} \cdot \mathrm{HCO}_{3}$ salts, where $\mathrm{ASM}$ is an "amine-based structural motif" ligand. ${ }^{[7]}$ Crystal structures of all three compounds are included and each of them contains conventional bicarbonate anions hydrogen bonded in a commonly observed dimeric arrangement.

In their published work, Ackermann et al. report that the hydrogen atom of the unusual $\left[\mathrm{O}_{2} \mathrm{C} \cdots \mathrm{OH}\right]^{-}$anion was located in the Fourier map, but that it was subsequently fixed to an ideal hydroxide geometry and refined using a riding model. To us it seems strange that such an important atom in the structure was not refined isotropically if it was clearly visible in the Fourier map. In fact, the data deposited by the authors in the CCDC $^{[5]}$ contains an isotropically refined hydrogen atom, however, the reported $U_{\text {iso }}$ value is a nonsensical $0.9(3)$. The authors do point out that the size and shape of the thermal ellipsoid of the hydroxide oxygen atom indicates rotational disorder. Based on our results, this ellipsoid becomes completely reasonable when using the acetate anion in the structural refinement (see Figure 1). The presence of a hydroxyl group that is not engaged in hydrogen bonding is certainly not unprecedented, but it does raise 
significant concern as to whether the correct assignment has indeed been made. We also note that in our refinement of the acetate salt, the hydrogen atoms on the acetate methyl carbon were clearly visible in the Fourier map and could be refined isotropically. In fact, a disordered model for the methyl group was found to give the optimal fit.

Considering the chemistry involved in the preparation of the putative salt, $\left[n \mathrm{Bu}_{4} \mathrm{~N}\right]\left[\mathrm{O}_{2} \mathrm{C} \cdots \mathrm{OH}\right]$, the origin of an acetate anion seems puzzling. We can therefore see reasons for why alternative assignments of the crystallographic data were not considered. A possible source of acetate could be the $\left[n B u_{4} N\right] \mathrm{OH}$ solution which does contain trace amounts of other cations and anions. Perhaps a more plausible explanation is the cleavage of diethyl ether during the distillation, which could have produced some ethanol that, in the presence of adventitious oxygen, could form acetate. The required oxygen may have been present in the original hydroxide solution. Alternatively, the diethyl ether might initially have been contaminated with small amount of ethanol, the precursor to most commercial sources of diethyl ether. Additionally, adventitious oxygen in diethyl ether could have initiated the formation of peroxides whose decomposition pathway includes acetic acid or one of its esters. ${ }^{[8]}$ Under the reported preparative conditions, these species could certainly be hydrolyzed and deprotonated to form acetate. In all of these scenarios, a small amount of the acetate salt could be present in the bulk powder and crystallize out from the ether solution. Our crystallization experiments clearly showed that $\left[n \mathrm{Bu}_{4} \mathrm{~N}\right]\left[\mathrm{O}_{2} \mathrm{CCH}_{3}\right]$ is only sparingly soluble in ether and readily forms single crystals of excellent X-ray quality.

\section{Conclusion}

In summary, our detailed experimental evidence casts serious doubts on the claims made by Ackermann et al. in the paper "Crystallographic Snapshot of an Arrested Intermediate in the Biomimetic Activation of $\mathrm{CO}_{2}$ ". We believe that the authors have synthesized and spectroscopically characterized powdered bicarbonate, $\left[n \mathrm{Bu}_{4} \mathrm{~N}\right] \mathrm{HCO}_{3}$, and carried out an X-ray crystallographic study on a single crystal of acetate, $\left[n \mathrm{Bu}_{4} \mathrm{~N}\right]\left[\mathrm{O}_{2} \mathrm{CCH}_{3}\right]$. We therefore consider that all extrapolations from the putative structural model proposed in the original study are invalid. Considering the general importance of the original publication, the activation of $\mathrm{CO}_{2}$ under mild 
conditions and synthetic mimics to enzymatic functions, we feel it extremely important that the compound reported by Ackermann et al. is correctly identified.

\section{References}

[1] S. L. Ackermann, D. J. Wolstenholme, C. Frazee, G. Deslongchamps, S. H. M. Riley, A. Decken and G. S. McGrady, Angew. Chem. Int. Ed. 2015, 54, 164-168.

[2] L. J. Murphy, K. N. Robertson, R. A. Kemp, H. M. Tuononen, J. A. C. Clyburne, Chem.Commun. 2015, 51, 3942-3956.

[3] L. J. Murphy, K. N. Robertson, S. G. Harroun, C. L. Brosseau, U. WernerZwanziger, J. Moilanen, H. M. Tuononen and J. A. C. Clyburne, Science 2014, 344, $75-78$.

[4] X. Zhang, U. Gross and K. Seppelt, Angew. Chem., Int. Ed. Engl. 1995, 34, 18581860.

[5] The Cambridge Structural Database: F. H. Allen, Acta Cryst. 2002, B58, 380-388.

[6] Mercury 3.3.1: C. F. Macrae, I. J. Bruno, J. A. Chisholm, P. R. Edgington, P. McCabe, E. Pidcock, L. Rodriguez-Monge, R. Taylor, J. van de Streek, P. A. Wood, J. Appl. Cryst. 2008, 41, 466-470.

[7] S. Dalapati, S. Jana, R. Saha, M. A. Alam, N. Guchhait, Org. Lett. 2012, 14, 32443247.

[8] S. Di Tommaso, P. Rotureau, O. Crescenzi and C. Adamo, Phys. Chem. Chem. Phys. 2011, 13, 14636-14645. 